\title{
Dogmas de fe: Realidades históricas y políticas
}

\author{
Roberto Valdés Valle \\ Departamento de Filosofía \\ UCA, San Salvador
}

\begin{tabular}{|ll} 
RESUMEN: El tema del dogma se suele & ABSTRACT: Frequently, the dogma \\
entender al margen de las determinaciones & issue is understood without considering \\
bistóricas. Por eso, se suele afirmar injus- & the historic factors. For that reason, an \\
tificadamente que desde el inicio de su & unjustified assertion is that the Church bas \\
historia la Iglesia ha mantenido un unico & maintained a single discourse on dogma \\
discurso sobre este respecto. Sin embargo, & since its beginning. However, an analysis \\
un análisis de la bistoria de estas ideas no & of the history of these ideas does not resist \\
resiste semejante interpretación. Es posible & such interpretation. It is possible to think \\
pensar estas realidades desde nuevas her- & these realities from new hermeneutics or \\
menéuticas o filosofías. Para este cometi- & philosophies. The author uses the reflec- \\
do, el autor echa mano de las reflexiones & tions of Andrés Torres Queiruga and \\
desarrolladas por Andrés Torres Queiruga & Xavier Zubirifor this purpose. \\
$y$ Xavier Zubiri. & \\
\hline
\end{tabular}

En este trabajo quisiera abordar dos problemas relacionados con los denominados dogmas de fe, tal y como son entendidos por la Iglesia católica romana. En primer lugar, quisiera examinar el origen histórico y el sentido que tiene el concepto de dogma, y en segundo lugar, examinaré el tema de la evolución de los dogmas. ¿Con qué objetivo? ¿Qué importancia puede tener para nuestro tiempo y situación abordar problemas tan abstractos como estos? La importancia es ciertamente mucha, aunque cada vez se hace más difícil captarla debido a presiones ideológicas no siempre evidentes a simple vista. 
Y es que por lo general se tiende a afirmar de manera ideologizada que la Iglesia ha poseído desde siempre una noción clara y distinta de temas tan determinantes como el dogma y cómo ha de entenderse la evolución de éstos; se suele afirmar injustificadamente que desde el inicio de su historia la Iglesia ha mantenido un único y mismo discurso, el que se presenta como oficial hoy; y que por tanto toda reflexión teológica sobre semejantes temas debe limitarse a esclarecer lo ya sabido, pero nunca a introducir nuevas hermenéuticas o, mucho más grave aún, a mostrar los entresijos políticos que realmente forjaron las construcciones ideológicas que todavía se exhiben como "dádivas inmerecidas" de una divinidad ahistórica.

Sin embargo, un somero análisis de la historia de estos conceptos o ideas, como el que se realizará a continuación, no resiste semejante interpretación de la historia del dogma. En este contexto, quisiera mostrar que sí es posible, y siempre ha sido posible, pensar estas realidades desde nuevas hermenéuticas o filosofías. Para ejemplificar esta posibilidad siempre abierta, me serviré de las reflexiones desarrolladas por Andrés Torres Queiruga y Xavier Zubiri ${ }^{2}$ en algunos de sus textos escritos entre finales de los años 60 y principios de los 70 del siglo pasado, precisamente cuando la discusión sobre el dogma y su evolución se encontraba en su punto más álgido, luego de la renovación teológica que estimuló el concilio Vaticano II.

Así, el presente trabajo se dividirá en tres partes. En la primera voy a examinar el origen y significado del concepto de dogma; en la segunda haré lo mismo respecto del tema de la evolución del dogma. Finalmente, en la tercera parte, presentaré de manera sintética la forma en que Torres Queiruga y Zubiri afrontaron los problemas teóricos que plantea la historia del dogma.

\section{1.) Origen y significado del concepto de dogma y su problemática}

\subsection{Concepción de dogma según el concilio Vaticano I}

El punto culminante para la formulación de la actual concepción del dogma católico se encuentra en la Constitución Dei Filius, proclamada durante el concilio Vaticano I, el 24 de abril de 1870. La definición, que Mansini califica de "técnica", se encuentra en el 3011 del Denzinger (DS) y reza de la siguiente manera: 
Ahora bien, deben creerse con fe divina y católica todas aquellas cosas que se contienen en la palabra de Dios escrita o tradicional, y son propuestas por la Iglesia para ser creídas como divinamente reveladas, ora por solemne juicio, ora por su ordinario y universal magisterio ${ }^{4}$.

Bonifazi, parafraseando esta declaración del concilio, afirma que el dogma "sirve para designar las verdades reveladas por Dios y definidas como tales por el magisterio, o sea, las que el concilio Vaticano I llamó verdades de fe divina y católica ${ }^{5}$. En cambio, Beinert, tratando de interpretar lo dicho por el concilio, dirá que el objetivo último del dogma es "declarar de una vez para siempre qué afirmaciones son importantes

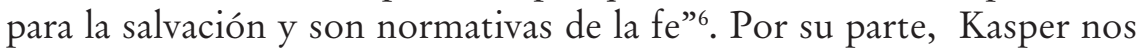
explica que en un sentido amplio, "dogma es la verdad de Dios para los hombres definitivamente revelada por Jesucristo y testificada obligatoriamente por la Iglesia"'. Y Tamayo, con una intención más crítica, en el sentido que relativiza el valor absoluto del dogma, dirá que:

No son la única expresión de la fe, pero sí una de las formas más cualificadas que tiene la revelación de manifestarse y uno de los cauces a través de los cuales se expresa el mensaje cristiano en los diferentes contextos socio-culturales ${ }^{8}$.

Ejemplos de este tipo de afirmaciones serían los dogmas cristológi$\cos ^{9}$, los trinitarios ${ }^{10}$, los marianos ${ }^{11}$ y los que se refieren a la infalibilidad del Papa'. Tal vez sea bueno citar un par de estas formulaciones dogmáticas para que nos demos cuenta más claramente de qué se está hablando aquí. En todos ellos se encuentra la declaración formalmente dogmática y a continuación las consecuencias de su no aceptación. Se va a comenzar por recordar las consecuencias de no aceptar tales dogmas. En el caso de la definición de la Inmaculada Concepción de María, las consecuencias son las siguientes:

Por lo cual, si alguno, lo que Dios no permita, pretendiere en su corazón sentir de modo distinto a como por Nos ha sido definido, sepa y tenga por cierto que está condenado por su propio juicio, que ha sufrido naufragio en la fe y se ha apartado de la unidad de la Iglesia, y que además, por el mismo hecho, se somete a sí mismo a las penas establecidas por el derecho, si, lo que en su corazón siente, se atreviere a manifestarlo de palabra o por escrito o de cualquier otro modo externo (DS, 2804). 
Recordemos ahora las declaraciones de los llamados dogmas marianos. El dogma de la Inmaculada Concepción de María, fue definido por el Papa Pío IX el 8 de diciembre de 1854 en la Bula Ineffabilis Deus:

Con la autoridad de nuestro Señor Jesucristo, de los bienaventurados Apóstoles Pedro y Pablo y con la nuestra declaramos, proclamamos y definimos que la doctrina que sostiene que la beatísima Virgen María fue preservada inmune de toda mancha de la culpa original en el primer instante de su concepción por singular gracia y privilegio de Dios omnipotente, en atención a los méritos de Cristo Jesús Salvador del género humano, está revelado por Dios y debe ser por tanto firme y constantemente creída por todos los fieles (DS, 2803).

El dogma de la “Asunción de María al cielo” fue definido por el Papa Pío XII el 1 de noviembre de 1950 en la Constitución Apostólica Munificentissimus Deus:

Por la autoridad de nuestro Señor Jesucristo, de los bienaventurados Apóstoles Pedro y Pablo y nuestra, proclamamos, declaramos y definimos ser dogma divinamente revelado: Que la Inmaculada Madre de Dios, siempre Virgen María, cumpliendo el curso de su vida terrestre, fue asunta en cuerpo y alma a la gloria celestial (DS, 3903).

Pero el concilio Vaticano I fue más allá de la definición arriba citada de dogma, pues estableció además ciertos criterios definitivos, que siguen vigentes hasta la actualidad, para la comprensión de los mismos: en primer lugar, criterios que ayudan a determinar la naturaleza de los dogmas; y, en segundo lugar, criterios que ayudan a zanjar el espinoso problema de la historicidad de los dogmas y sobre la posibilidad de encontrar o postular nuevas y mejores hermenéuticas para los dogmas ya establecidos. A continuación se especifica en qué consiste cada uno de estos problemas.

\section{a) La naturaleza de los dogmas}

En primer lugar, el concilio Vaticano I estableció que los dogmas no pueden entenderse como resultados de "un hallazgo filosófico que deba ser perfeccionado por los ingenios humanos” (DS, 3020), es decir, los dogmas - o la doctrina de la fe (como los llama el concilio) - no son producto de la reflexión humana (de los creyentes o de los teólogos), no es algo a lo que se llega, sino simplemente algo que ha sido "entre- 
gado a la Esposa de Cristo como un depósito divino" que debe ser "fielmente guardado e infaliblemente declarado" (DS, 3020; los énfasis son míos). En otras palabras, los dogmas no son resultado de la dialéctica de la Iglesia o sus miembros con el mundo. Es más bien, como dice el concilio, un depositum; y por depósito debe entenderse precisamente lo siguiente:

El depositum... no es algo que se han imaginado los hombres, sino cosa que han recibido (de Dios); no es algo que ellos han compuesto (inventum), sino cosa que a ellos les ha sido confiada (por Dios); una cosa, por consiguiente, que no es fruto de la ingeniosidad humana, sino de la enseñanza (recibida); no de uso privado, arbitrario (privatae usurpationis), sino tradición pública (es decir, que a todos obliga); una cosa no extraída de ti, sino traída a ti..., donde tú no eres autor, sino custodio; no maestro, sino discípulo; no guía, sino discípulo ${ }^{13}$.

No cabe duda de que estas características apuntan a certificar como únicamente válida una comprensión intemporal, inmutable, literal o fundamentalista de las declaraciones dogmáticas; y lo más grave de esta comprensión es que puede conducir, como muy bien señala Bonifazi, al "inmovilismo eclesial” y a hacer mucho más difícil todo diálogo intracristiano y ecuménico.

... los dogmas aparecen como una de las fuentes principales del inmovilismo eclesial. Una institución histórica basada en dogmas inmutables aparece fácilmente como incapaz de seguir el ritmo de evolución de la historia; parece radicalmente imposibilitada para historizarse y renovarse $\mathrm{e}^{14}$.

En definitiva, para el concilio Vaticano I, los dogmas son verdades que han sido entregadas a la Iglesia como realidades ya hechas, no por manos humanos, sino divinas; son por tanto afirmaciones definitivas, acabadas que sólo deben ser recibidas pasivamente y transmitidas a los creyentes para, si es posible, su inmediata aceptación. Se tratan de verdades literalmente "bajadas del cielo". Y por si quedara duda de lo anterior, en el Decreto del Santo Oficio Lamentabili, del 3 de julio de 1907, por el que se condena al Modernismo, se establece como absolutamente falsa la siguiente afirmación modernista que apunta precisamente a considerar lo dogmas como verdades "no bajadas del cielo". La afirmación modernista condenada por el Decreto del Santo Oficio es la siguiente: 
Los dogmas que la Iglesia presenta como revelados, no son verdades bajadas del cielo, sino una interpretación de hechos religiosos que la mente humana se elaboró con trabajoso esfuerzo" (DS 3422).

Aquí tenemos en gran parte definida la naturaleza esencial de los dogmas: son afirmaciones que contienen verdades de carácter absoluto, son realidades estrictamente intelectuales propuestas por el Magisterio para ser aceptadas por los fieles como verdades reveladas o de fe, y por ello tienen carácter objetivo y absoluto.

\section{b) Historicidad y hermenéutica de los dogmas}

En segundo lugar, y partiendo del primer grupo de características ya mencionadas, el concilio establece que nada se puede añadir y nada se puede quitar a las proposiciones dogmáticas tal y como fueron declaradas; pero, sobre todo, no se puede postular la existencia de un significado mejor o más comprehensivo del originalmente dado cuando se proclamó oficialmente el dogma. Así, toda posibilidad de una nueva hermenéutica de los dogmas queda definitivamente rechazada.

... hay que mantener perpetuamente aquel sentido de los sagrados dogmas que una vez declaró la santa madre Iglesia y jamás bay que apartarse de ese sentido so pretexto y nombre de una más alta inteligencia (DS, 3020; los énfasis son míos).

Aquí se está apuntando al carácter a-histórico e inmutable de los dogmas, a la imposibilidad absoluta de que el significado de las proposiciones que los contienen pueda ser cambiado o reinterpretado desde nuevas perspectivas. En el fondo, lo que tenemos aquí es el mismo problema que tuvieron que enfrentar los investigadores católicos de la Biblia, quienes, en la primera mitad del siglo XX, clamaban por un espacio libre de la dogmática y del Magisterio para profundizar en el conocimiento científico de las Escrituras desde la perspectiva de la historia, de la historicidad o del historicismo; sólo que en nuestro caso no se trata de la historicidad o no de la revelación, sino de la historicidad de los dogmas mismos. Fue el problema que enfrentaron los teólogos "modernistas". En ese sentido, las condenas al Modernismo en el decreto del Santo Oficio Lamentabili y después en la encíclica de Pío X, Pascendi dominici gregis, del 8 de septiembre de 1907, vendrán a reafirmar el carácter a-histórico de los dogmas y a cerrar toda posibilidad de nuevas hermenéuticas de los mismos. Este rechazo se volvió a reforzar en la encíclica de Pío XII, Humani generis, del 12 de agosto de 1950: 
... es intento de algunos atenuar lo más posible la significación de los dogmas y librar al dogma mismo de la terminología de tiempo atrás recibida por la Iglesia, así como de las nociones filosóficas vigentes entre los doctores católicos, para volver en la exposición de la doctrina católica el modo de hablar de la sagrada Escritura y de los santos Padres (DS, 3881).

Además, reducida la doctrina católica a esta condición, piensan que queda así abierto el camino por el que satisfaciendo a las exigencias actuales pueda expresarse también el dogma por las nociones de la filosofía moderna, ya del "inmanentismo", ya del "idealismo", ya del "existencialismo", ya de cualquier otro sistema (DS, 3882).

Muy acertadamente muestra Torres Queiruga que las resistencias a las nuevas hermenéuticas dogmáticas han terminado siendo, "curiosamente", mucho más fuertes e intransigentes a nivel oficial de lo que fueron las resistencias respecto de las nuevas hermenéuticas bíblicas:

No se puede reinterpretar la Escritura, si no se reinterpreta simultáneamente el contexto histórico en que nos es dado leerla. Momentos fundamentales de ese contexto son los dogmas. Y es curiosa la resistencia que el mundo católico opuso a la posible reinterpretación del dogma, basándose en su validez absoluta, cuando ya llevaba tiempo reinterpretando la Escritura, al fin y al cabo más absoluta, si así puede hablarse... Entonces apareció —está apareciendo- claro que también el dogma tiene que ser reinterpretado sin que por ello sufra menoscabo su absolutez bien entendida ${ }^{15}$.

Creo que es necesario especular brevemente sobre una posible causa de estas resistencias, más allá de lo meramente político. Quizá para el Magisterio resulta inconcebible una nueva hermenéutica, no porque la Iglesia "no lo quiera" o se cierre a posibles nuevas interpretaciones del dogma, sino por la comprensión que tiene de la naturaleza misma de lo dado a ser custodiado: que es precisamente, como ya se dijo, algo "dado", "finalizado", “cristalizado", por ser algo "bajado del cielo". Y esto remite, en última instancia, a una manera muy particular de entender la revelación, a una manera que podría calificarse de "tradicional", que tiende a definir la revelación como una especie de "dictado" de proposiciones absolutamente verdaderas. Pero si no es ésta la única manera de concebir en qué consiste la revelación, entonces obligaría a plantear

\section{1}


desde otra perspectiva la naturaleza e historicidad de los dogmas: por poner un ejemplo muy claro, para autores como Rahner y Kasper, la revelación debe entenderse no como un dictado, sino como la autocomunicación de Dios por Jesucristo en el Espíritu Santo ${ }^{16}$.

Ahora bien, como ya insinuaba al inicio, se trata de una comprensión del dogma que con sus más y sus menos la Iglesia sigue manteniendo como vigente hasta el presente, con todas sus implicaciones. Así, resulta interesante comprobar, por ejemplo, que durante la discusión generada por los polémicos libros de Hans Küng sobre la Iglesia ${ }^{17}$ y sobre la infalibilidad del $\mathrm{Papa}^{18}$, la Congregación para la Doctrina de la Fe publicó el 24 de junio de 1973 la declaración Mysterium ecclesiae en la que, después de citar el ya decisivo canon del concilio Vaticano I, afirma que

... el objeto de la fe católica, que se conoce con el nombre de dogmas, es necesariamente, y lo fue en todo tiempo, la norma inmutable no sólo para la fe, sino también para la ciencia teológica (DS, 4536, los énfasis son míos).

Aquí la Congregación está reafirmando una vez más la naturaleza “cristalizada” de los dogmas. Se está reafirmando, pues, que la declaración dogmática es verdadera tal y como está formulada, sin posibilidad alguna de cambio en su interpretación, o una nueva hermenéutica:

De ningún modo está permitido a los fieles admitir en la Iglesia sólo una fundamental permanencia de la verdad, que, como algunos sostienen, se puede conciliar con errores diseminados por doquier en las sentencias definitivas del magisterio, así como en el consentimiento ajeno a toda duda del pueblo de Dios en materia de fe y costumbres (DS, 4537).

Pero, por otro lado, el documento está avanzando un par de ideas que no habían aparecido hasta ahora en esta exposición, pero que terminan de delimitar el tema la naturaleza de los dogmas: la idea de que los dogmas deben ser entendidos como "normas" de tipo jurídico, y además se enfatiza que ésta ha sido la forma común de concebirlos a lo largo de todos los siglos de existencia de la Iglesia., cosa que, como se verá, también es discutible.

Si se quisiera resumir críticamente toda esta concepción del dogma, se diría que la a-historicidad, el fundamentalismo, la inmutabilidad y el legalismo de los dogmas católicos son la herencia más importante que nos dejó el concilio Vaticano I. Y por si cabe alguna duda sobre lo dicho, los padres conciliares muy claramente establecieron que afirmar 
lo contrario sobre las declaraciones dogmáticas debe ser considerado "anatema”, es decir, sujeto a condena, maldición o excomunión de la fe:

Si alguno dijere que puede suceder que, según el progreso de la ciencia, haya que atribuir alguna vez a los dogmas propuestos por la Iglesia un sentido distinto del que entendió y entiende la misma Iglesia, sea anatema (DS, 3043).

\subsection{Algunas consideraciones críticas sobre el origen de la noción de dogma}

No obstante lo contundente de las declaraciones conciliares y la censura a la teología modernista, se debe contrastar estas declaraciones oficiales con los resultados de investigadores como Bonifazi, Tamayo y Mansini sobre todas estas cosas. Bonifazi sostiene, por ejemplo, que "está históricamente comprobado que ni entre los padres ni durante la edad media, el término "dogma”, tomado en sí mismo, se usó en el sentido estricto actual”" Por su parte, Tamayo y Mansini coinciden en que la definición del concilio tiene graves limitantes, si es tomada de manera absoluta, sin posibilidad de discusión o matización o, lo que es más grave, si se asume falsamente que ha sido la única concepción de dogma desde el inicio mismo de la Iglesia. Tamayo, retomando las observaciones de Rahner, Lehmann y Kasper a esta definición, dirá que

La compresión del dogma, tal como aparece en el Vaticano I, no recoge, ni con mucho, la riqueza y la complejidad que se encierra en la tradición de la Iglesia. El concilio no describe de manera exhaustiva todos los elementos constitutivos del dogma. Carga excesivamente el acento en el elemento formal de la autoridad, descuidando otros no menos importantes ${ }^{20}$.

Por su parte, Mansini, haciendo previamente un breve recorrido sobre el origen histórico de esta definición oficial o "técnica" del dogma, hará una valoración positiva y negativa de la misma:

La formulación de esta noción técnica presenta a la vez ventajas e inconvenientes, como en cualquier objetivación: es útil, tanto para fines teológicos como de controversia (y ecuménicos), haber definido este objeto de modo exacto y preciso; es peligro$s a$, ya que esta definición induce a una consideración jurídica y estrecha del dogma, aislada de las realidades más amplias de la revelación y de la fe, y a una cierta reducción del verdadero objeto de la fe misma ${ }^{21}$. 
Si se fuera a resumir las principales críticas destacadas por estos autores, se tendrían los siguientes puntos: a) para Tamayo, esta formulación del dogma no da cuenta de la "riqueza" y "complejidad" que ha tenido el término "dogma" a lo largo de la historia de la Iglesia; b) como muy bien nota Mansini, se trata de una definición que surge al calor de la "controversia", en este caso de la controversia con el mundo moderno y el liberalismo de los siglos XVIII y XIX; c) se trata, por tanto, de una definición de tipo más jurídica o "jurídico-formal”; se trata más bien de una "norma", como matiza Tamayo, frente a una concepción más de carácter "teológica-filosófica", que era la que caracterizaba -como se verá- a las formulaciones hechas por los Padres de la Iglesia y durante toda la edad media. Desarrollemos un poco más este aspecto.

\section{a) Noción de dogma a partir de la Contrarreforma}

Tanto Mansini como Tamayo dirán que la "noción técnica” o "jurídico-formal” del dogma que canonizó el concilio Vaticano I "aparece por primera vez" en la obra De locis theologicis (1553), del teólogo español Melchor Cano (1509-1560), para quien el dogma debe entenderse como "verdad de revelación recibida de los apóstoles por la Iglesia, definida por un concilio ecuménico o por el papa o... mantenida de manera unánime y constante, por el pueblo de Dios”22. No hay que perder de perspectiva que Melchor Cano fue un importante teólogo de Trento; por tanto, su pensamiento está muy condicionado por la controversia con los protestantes. Mansini por su parte aclara que "el primero en expresar la moderna definición de dogma” fue Felipe Neri Chrismann (1751-1810) en su obra Regula fidei catholicae et collectio dogmatum credendorum (1792); sin embargo, Kasper puntualiza que esta definición de Neri fue en un primer momento criticada e incluso condenada por "minimalista"23.

Los investigadores coinciden, finalmente, en sostener que esta manera tan peculiar de entender el dogma tuvo su origen más remoto en el pensamiento de san Vicente de Lérins (muerto hacia el año 450), quien en su libro Commonitorium, compuesto hacia el 434, formuló lo que ha venido a llamarse con el paso del tiempo el "canon vicentiniano", la verdadera fuente de inspiración del concilio Vaticano I y de todo el pensamiento ortodoxo de la Iglesia católica desde entonces. El así llamado canon se formula de la siguiente manera:

Crezca, pues, y mucho e intensamente, la inteligencia, ciencia y sabiduría de todos y de cada uno, ora de cada hombre particu- 
lar, ora de toda la Iglesia universal, de las edades y de los siglos; pero solamente en su propio género, es decir, en el mismo dogma, en el mismo sentido, en la misma sentencia ${ }^{24}$.

El canon establece criterios importantes para clarificar las relaciones que deben existir entre dogma y evolución del dogma. Pero antes de profundizar sobre su sentido, es importante destacar también que los especialistas coinciden en que esta definición de Lérins pasó en su momento completamente desapercibida; en otras palabras, no fue tomada en cuenta ni durante el período de la Patrística ni durante la edad media. Vale la pena traer a colación lo que sobre este punto comentan Tamayo y Kasper, para obtener una pista que permita comprender las razones por las cuales el canon de Lérins comenzó a ser recuperado por la Iglesia hasta muchos siglos después de su formulación:

El punto de vista de Vicente Lérins apenas fue tenido en consideración durante la edad media. Su redescubrimiento se produce a partir del siglo XVI. Fueron los teólogos contrarios a los innovadores y, en general, la reflexión teológica elaborada entre Trento y el Vaticano I quienes se remitieron a él ${ }^{25}$.

La obrita de Vicente de Lérins permaneció olvidada durante toda la edad media y sólo empezó a influir después de su redescubrimiento por los humanistas en el siglo XVI, pero entonces lo hizo con fuerza (35 ediciones y 22 traducciones en el s. XVI). En cambio, se conocía el escrito de su alumno Gennadio de Marsella De ecclesiasticis dogmatibus. No obstante el concepto de dogma desempeña en la escolástica un papel relativamente insignificante ${ }^{26}$.

No cabe duda que la resurrección de Lérins se dio en el contexto de la controversia contra los protestantes en el siglo XVI. Pero en lo que no profundizan estos autores fue en las causas del olvido que sufrió Lérins. No está de más, pues, preguntarse por qué Lérins fue dejado de lado durante tanto tiempo. A este respecto, es interesante constatar que a Lérins se le suele considerar en los ambientes piadosos (en los santorales, por ejemplo) como "el santo que se equivocó", y se equivocó, según la Iglesia, en importantes cuestiones doctrinales. Baste citar un pequeño ejemplo de este tipo de literatura que además ofrece importante información que permite aclarar los motivos que llevaron a la marginación del pensamiento de Lérins durante siglos: 
Su singularidad (la de Vicente de Lérins) estriba en haber sido un santo que se equivocó en sus opiniones teológicas, lo cual a simple vista no deja de parecer chocante; se equivocó, hay que aclararlo, cuando lo que se discutía era aún una cuestión abierta, y sólo después de su muerte la Iglesia se pronunció en contra de sus tesis... Un temible polemista cuando se lanza al fragor de la discusión teológica, oponiéndose a san Agustín, con quien intercambia vehementes latines y complicados argumentos sobre el delicadísimo problema de armonizar gracia divina y libertad. En la querella del semipelagianismo parece que san Vicente se inclinó por soluciones que más tarde el magisterio había de rechazar, pero ahí está en la lista de los santos, apaciguado por el amor de Dios, que está más allá de las polémicas de los teólogos. ${ }^{27}$

Digamos, para comenzar, que Lérins redacta este canon también en un contexto de controversia, en un momento en el que las herejías afloran (arrianismo, donatismo, pelagianismo y semipelagianismo); en un momento, pues, en el que no resulta del todo claro quién tiene la verdad última sobre la doctrina cristiana. Y ese será precisamente el objetivo de su "canon": "descubrir los fraudes y evitar los lazos de los herejes recientes" 28 . Se trata, pues, de ofrecer criterios claros que permitan distinguir, en tiempos de confusión, la verdad del error por la aparición de nuevas ideas teológicas al interior mismo de la Iglesia. Se trata, por tanto, de establecer algunos criterios que permitan distinguir entre las formulaciones doctrinales ortodoxas y las heterodoxas.

Cuando una situación de confusión y duda doctrinal, como la descrita, sucede en la Iglesia —ocurrían y seguirán ocurriendo con bastante frecuencia después de Lérins-, Vicente ofrece los siguientes criterios de discernimiento: a) apelar en primer lugar a lo establecido en la Sagrada Escritura; b) pero si esta apelación no es suficiente, hay que recurrir a la tradición de la Iglesia católica, es decir a lo que ha sido creído en todas partes, siempre y por todos.

El recurso a la tradición y a la antigüedad se vuelven necesarios porque puede suceder que el error doctrinal sea mantenido por autoridades y autores muy respetables al momento de darse la controversia, y ser aceptado también por grandes porciones de la cristiandad. El ejemplo más claro de todo esto lo es sin duda el arrianismo, que al ser asumido casi en su totalidad por los pueblos germanos estuvo a punto de dividir 
en dos el Imperio romano ya entonces en proceso definitivo de cristianización. Pero en el caso desesperado de que la tradición no pueda por sí misma ofrecer una respuesta satisfactoria, Lérins establece las siguientes precisiones. Si también en la antigüedad nos encontramos con el error, habría que recurrir a lo establecido por los concilios o, como última medida, a "lo aprobado por aquellos que en diferentes épocas y lugares se mantuvieron siempre firmes en la unanimidad de la fe católica" ${ }^{29}$.

En el tiempo del propio Lérins, lo que lo motivó a formular su canon era la confusión que a su juicio estaban provocando las explicaciones sobre gracia y libertad desarrolladas por san Agustín y sus seguidores. Para Lérins, y según los estándares de su propio canon, las ideas de Agustín eran contrarias a la ortodoxia, a la verdad cristiana, es decir, contrarias a lo que fue creído en todas partes, siempre y por todos. Sin embargo, y esta es la ironía, hoy la Iglesia considera que las ideas teológicas de Lérins sobre gracia y libertad son heréticas, pues representan la postura denominada semipelagiana ${ }^{30}$, mientras que las opiniones de Agustín fueron asumidas como ortodoxas. Sin embargo, lo más sorprendente es que, después de todo, nos encontramos con que Lérins fue declarado santo; eso sí, como el "santo que se equivocó”. ¿Cómo se ha llegado a semejante situación?

Si hoy no se considera a Lérins como un hereje, sino más bien como un pensador "extrañamente" ortodoxo, se debe a que el Papa Benedicto XIV (1675-1758), en plena lucha con la modernidad, declaró que sus posturas no podían ser consideradas decididamente heréticas porque las mantuvo cuando la Iglesia toda no había dado su juicio final sobre las doctrinas de Agustín y las de los semipelagianos; esto sucedió hasta el 529 durante el concilio de Orange, unos 75 años después de la muerte de Lérins.

En resumen, frente a las doctrinas pelagianas y semipelagianas, el pensamiento de Agustín terminó imponiéndose en la teología de la Iglesia, y esto ayuda a explicar en gran medida el olvido o rechazo que experimentaron las posturas teológicas de Lérins sobre la gracia y la libertad, pero al mismo tiempo se olvidaron sus entonces "incómodos" criterios para distinguir entre posturas ortodoxas y heréticas ${ }^{31}$. En todo caso, es claro, que la visión de Lérins comenzó a tener relevancia a partir del concilio de Trento (1545-1563), es decir como instrumento de ataque a las posturas de los reformadores protestantes para quienes el único y verdadero dogma sólo se encuentra en la Escritura y no en

\section{7}


lo definido por el Magisterio. Eso es lo que explicaría la multiplicación vertiginosa de impresiones que tuvo su obra en el siglo XVI. Me parece importante recalcar esta idea: el objetivo ideológico último de la resurrección de Leríns era contar con un poderoso argumento en contra de las tesis de los protestantes. Para la Iglesia católica la postura reformista de ninguna manera era aceptable; el criterio para distinguir la ortodoxia o no de una idea o dogma, no podía ser sólo la Escritura:

La Reforma protestante hace de la Escritura fuente y norma — más aún, última instancia - de toda doctrina y autoridad definitiva, a la que todo creyente ha de acudir. Las afirmaciones dogmáticas gozan de la obligatoriedad sólo en la medida en que remiten a la Escritura. Para los reformadores, los credos y confesiones de fe son simplemente compendios de las enseñanzas bíblicas. Son necesarios en cuanto cumplen ese cometido, pero en ningún caso se consideran suficientes ${ }^{32}$.

Todo esto nos lleva a plantearnos la interrogante sobre cómo se entendió el dogma antes de Trento y antes del Vaticano I, es decir antes de que la Iglesia comenzara su disputa con los protestantes y con los liberales.

\section{b) Noción de dogma antes de la Contrarreforma}

En este punto resulta también interesante comprobar que la mayoría de los investigadores del tema, en algún momento o en otro, se ven obligados a plantear el problema del significado original y la evolución semántica que ha experimentado el concepto de dogma a lo largo de la historia. Este aspecto me parece fundamental para mostrar que contrario a lo que estipuló el concilio Vaticano I - y sobre todo la Declaración Mysterium ecclesiae de 1973-, la idea de dogma no ha sido siempre la misma a lo largo de la historia de la Iglesia. Voy a resumir a continuación los principales momentos en la evolución de este concepto, tal como es presentado por los investigadores que he consultado.

Algunos como Kasper se remontan hasta la concepción que tenía Platón sobre la palabra "dogma”. Dirá que en tiempos de Platón "dogma" era simplemente "lo que a todos o a muchos parece correcto"33. Ahora bien, esto que parece correcto puede ser "una opinión, doctrina, principio"; pero también "dogma” puede entenderse como aquello "que una asamblea o autoridad tiene por correcto", lo cual se traduce en "una resolución, un decreto o un edicto”. Originalmente había, pues, según 
Kasper, dos sentidos para la palabra dogma: un "sentido filosófico" y un "sentido jurídico", que es el que ha terminado por imponerse en la actualidad. En la Biblia, observan Kasper y Tamayo, la palabra dogma fue utilizada sobre todo en el sentido jurídico, aunque siempre es posible encontrar el otro significado, más filosófico. Sin embargo, durante la Patrística, se dio una inversión: el sentido más utilizado fue el filosófico, y el jurídico tuvo menor relevancia, aunque siempre era posible encontrar ambos:

Ya los padres apostólicos trasladaron el uso lingüístico de Flavio Josefo y de Filón al contexto cristiano aplicando el concepto de dogma o dogmas a las doctrinas y mandatos de Jesús... Los apologetas continuaron tomando el concepto de dogma en su sentido filosófico..., oponen los dogmas cristianos a los dogmas de los filósofos. Orígenes habla expresamente de los dogmas de Dios distinguiéndolos de las doctrinas humanas. Aquí se toca ya un motivo fundamental que desde Pablo y los apologetas y pasando por Vicente de Lérins se mantiene hasta el Vaticano I. Pero el sentido jurídico también se retiene... ${ }^{34}$

Por su parte, Tamayo nos aclara que los Padres Apostólicos -es decir los autores que la tradición ha considerado como los discípulos y sucesores directos de los primeros apóstoles de Jesús- utilizaron la palabra "dogma” para referirse a "la enseñanza de Jesús y de los apóstoles" pero en materia de comportamiento moral y no en términos de verdades teóricas o de fe:

En el caso de Ignacio de Antioquía se establece una conexión esencial entre los dogmas del Señor y el ministerio jerárquico. Dogma vendría a designar la obligatoriedad de la palabra de Jesús en la praxis de los cristianos. Se trata, por tanto de normas de comportamiento que han de practicar los seguidores de Jesús ${ }^{35}$.

Mansini concluirá también que tanto en el Nuevo Testamento como en el cristianismo primitivo, "dogma es ya como una realidad viva, pero sin poner gran énfasis sobre una estandarización de la fórmula verbal”, y reafirmará la idea de que es sólo a partir del siglo XVI, es decir con la obra de Cano primero y luego con la de Chrismann, "hay una posesión refleja de la realidad del dogma, pudiendo encontrarse una expresión de tal posesión en la Pastor aeternus" ${ }^{\prime 3}$. 
Finalmente se debe decir que también Tomás de Aquino, durante la edad media, entenderá la palabra dogma primordialmente en su sentido filosófico, es decir de doctrina, y no como algo jurídico o norma a ser aceptada como un decreto legislativo o judicial. Citando a Rahner y a Lehmann, Tamayo dirá, que lo esencial del dogma para Aquino está o debe buscarse en "su correspondencia con la fe" ${ }^{37}$, es decir con la totalidad de la verdad revelada y no con una afirmación aislada de tipo jurídico.

En definitiva, se podría decir con Tamayo que tres han sido "las causas fundamentales del proceso tan restrictivo que ha sufrido el término (dogma)". Estas son: a) "la pérdida del sentido de la totalidad", al dejar de lado la perspectiva de totalidad de la que hablaba Aquino y centrándose más bien "en fórmulas aisladas"; b) "el paso de una fundamentación teológica del dogma”, que sería lo que predominó durante la Patrística y la Edad Media, a "una fundamentación jurídico-formal”; y c) "la gradual separación entre doctrina y oración", o dicho con otras palabras, "la pérdida del carácter doxológico y el paso de las confesiones de fe a las formulaciones doctrinales" ${ }^{38}$.

Hasta aquí el examen de los orígenes de la actual formulación del dogma. He tratado de clarificar qué se entiende por dogma en la Iglesia católica y cuáles son los principales problemas o críticas que enfrenta esta concepción. He ido destacando también la manera y los motivos que hicieron posible la construcción de una noción de dogma bastante restringida, jurídica, absoluta e inmutable, concepción que ha servido sobre todo a partir del siglo XVI como instrumento de lucha en contra de las teorías, primero, de los teólogos protestantes y, luego, de los llamados "modernistas". Sin embargo, todo lo anteriormente discutido constituye sólo la primera parte del tema que quisiera abordar en este trabajo. El segundo aspecto que me he propuesto examinar es el problema de la evolución del dogma. Por tanto, en lo que sigue haré, como en las páginas anteriores, una exposición de los principales aspectos que están involucrados en esta temática de la evolución del dogma.

\section{El problema de la evolución del dogma}

Para Torres Queiruga, el tema de la evolución del dogma debe ser entendido en un doble sentido. El primero de ellos hace referencia a qué relación existe entre revelación y dogmas, sobre todo respecto de los dogmas que se podrían llamar "nuevos", es decir que no se tenían como 
tales antes de su proclamación formal. Me refiero, por ejemplo, a los dogmas marianos y al de la infalibilidad del Papa. Este primer sentido apunta al problema de la evolución del dogma.

El segundo sentido, en cambio, apunta en otra dirección: al problema de si el significado de los dogmas ya definidos es histórico o perfeccionable. Es un aspecto que ya antes se había señalado al hablar del carácter intemporal y a-histórico de los dogmas, es decir, el problema de si es posible una mejor comprensión de los dogmas ya definidos, una comprensión incluso mejor a la originalmente establecida. Ya se ha visto que el concilio Vaticano I dio un rotundo no a esta segunda posibilidad, lo cual no quiere decir que la disputa haya desaparecido sólo por lo afirmado taxativamente por el concilio. Torres Queiruga resume ambas cuestiones de la siguiente manera:

Con esta problemática (la aparición de nuevos dogmas) se fue entrecruzando otra distinta, que dentro del catolicismo, fue iniciada por la Escuela de Tubinga y por J. H. Newman, y acabó por imponerse gracias al impacto del Protestanismo liberal y del Modernismo. Ahora es el concepto mismo de dogma el que centra el problema: tanto en su licitud (Protestantismo liberal: problema de la helenización) como en su inmutabilidad y validez (Modernismo). Esto último, principalmente, introduce un concepto distinto de evolución: no se trata ya —al menos no se trata únicamente- de que aparezca o no un nuevo dogma, sino de la evolución del dogma o de los dogmas ya existentes; no ya, por ejemplo, cómo se deduce el dogma de la Inmaculada del dogma de Cristo, sino cómo surge y cómo ha de entenderse el dogma mismo de Cristo ${ }^{39}$.

En lo que sigue, me voy a centrar únicamente en la primera de las problemáticas apuntadas, puesto que la segunda ya fue esclarecida en la primera parte de este trabajo. Aquí, pues, me concentraré en el problema de si se ha logrado dar una explicación satisfactoria al problema de cómo explicar este supuesto "aparecer" de nuevos dogmas desde otros; o, para seguir con el ejemplo que nos propone Torres Queiruga, cómo se deduce el dogma de la Inmaculada Concepción de María del dogma de Cristo.

\subsection{El problema de la aparición de nuevos dogmas desde otros anteriormente establecidos}

Quizás sean Tamayo y Beinert quienes han logrado explicitar con

\section{1}


toda claridad en qué consiste esta problemática. Para Tamayo el problema se plantea como sigue. Se parte del hecho de que la Iglesia ha definido como verdades de fe o reveladas, es decir como dogmas que deben ser creídos sin discusión, algunas doctrinas que en definitiva no tienen equivalencia o fundamento en la Biblia. Para Beinert, ejemplos claros de éstos serían los últimos dogmas marianos de la Inmaculada Concepción (1854) y de la Asunción de María (1950), y los dogmas sobre la infalibilidad del Papa (1870). Beinert enfatiza que con semejantes declaraciones, "el magisterio pareció convertirse de una instancia que enjuiciaba los dogmas en otra que los desarrollaba" ${ }^{40}$. Es más, Tamayo dirá que "no parece que pueda asegurarse con probabilidad histórica que dichas verdades (dogmas) existieran en épocas anteriores a las definiciones dogmáticas”"1. Y la cuestión se complica mucho más, según Tamayo, si tomamos en cuenta que "existe una enseñanza universal admitida por el magisterio, según la cual la revelación termina con la generación de los apóstoles y ha sido recogida en los escritos del NT"42.

Si todo esto es así, resulta evidente que teológicamente se deba dar una explicación de cómo estas supuestas verdades de fe, que aparentemente no están contenidas en la revelación original, deben ser admitidas y enseñadas como parte de la misma. Una vez más, Torres Queiruga ha recogido todas estas problemáticas con mucha claridad:

... el problema de la evolución del dogma se entiende muchas veces -hasta hace pocos años prácticamente siempre- como el problema de la aparición de nuevos dogmas. Tal es, en efecto, el fondo del planteamiento heredado de la escolástica post-tridentina -defensa, frente al protestantismo, de la aparición de "nuevos" dogmas- y tal ha sido en gran medida el trasfondo de la reviviscencia de la problemática, a propósito de la proclamación de los "nuevos" dogmas marianos. El problema se centra entonces en explicar cómo esos dogmas se derivan "homogéneamente" de los anteriores. Con lo cual los dogmas anteriores tienden a formar un corpus dado, obvio e inmutable en sí mismo ${ }^{43}$.

Este es en esencia el desafío al que tratarán de dar respuesta muchos autores católicos y protestantes desde entonces; pero no se puede olvidar que fueron los protestantes quienes desde finales del siglo XIX y principios del XX comenzaron a llamar la atención sobre esta aparente paradoja o contradicción que existe entre evolución del dogma y revelación. Las sospechas se fueron haciendo más fuertes en la medida en 
que la Iglesia católica seguía y seguía añadiendo "nuevas verdades de fe", al declarar, precisamente, los dogmas de la concepción de María y de la infalibilidad del Papa. En efecto, según Torres Queiruga, hacia 1909 Adolf von Harnack (1865-1930) negó de manera radical "toda continuidad entre la revelación... y el dogma”, puesto que la revelación tiene su fundamento en "la pura simplicidad del sentimiento", mientras que el dogma "no es más que el producto del espíritu griego en el terreno del evangelio". Más aún, para Harnack, "el dogma es un mero producto de la razón”, y descarta totalmente toda "continuidad” con el Evangelio. En ese sentido, la evolución dogmática, que es el tema que aquí nos interesa, es entendida como "una caída" o una degeneración que culmina tanto en el catolicismo griego como, sobre todo, romano ${ }^{44}$.

Como era de esperarse, el planteamiento tan radical de Harnack fue rechazado por la Iglesia católica romana, y los teólogos católicos de variadas tendencias fueron ensayando diferentes teorías que pudieran dar cuenta de una relación legítima entre las nuevas verdades de fe con la revelación inicial. La mayoría de los especialistas en el asunto coinciden en estos teólogos católicos desarrollaron unas tres o cuatro grandes teorías al respecto; pero como señala Beinert ninguna de ellas ha logrado alcanzar un consenso suficiente, "ninguna de estas tentativas de solución pudo imponerse", por lo que afirma que "hoy los teólogos son de la opinión de que no es posible establecer una teoría universal de la evolución de los dogmas" ${ }^{45}$. No obstante lo dicho por Beinert, lo cierto es que la Iglesia terminó por aceptar como la interpretación más cercana a la verdad aquella desarrollada por los pensadores neoescolásticos o neotomistas de principios del siglo XX. A continuación haré una apretada síntesis de las principales teorías desarrolladas durante los siglos XIX y XX, tal y como son presentadas por Kasper, Beinert, Mansini y Tamayo.

\subsection{Algunas teorías que explican la evolución del dogma}

a) Kasper, por ejemplo, habla de diferentes "teorías de la evolución del dogma”. La primera sería la propuesta neoescolástica, para la que la conexión entre revelación y evolución dogmática debe ser entendida como "una deducción puramente lógica por vía de conclusión" ${ }^{46}$. La segunda teoría sería la de M. Blondel, para quien "los dogmas no son tanto el resultado de una reflexión dialéctica sobre unos textos como la expresión de una realidad constante y probada en la vida” (Ídem). La tercera serían las aportaciones de la Escuela protestante de Tubinga, y 
las del cardenal J. H. Newman. Así, para la Escuela de Tubinga, influida por el idealismo alemán, los dogmas serían una especie de "autointerpretación dialéctica de la idea del cristianismo en el paso a través de sus distintos opuestos". Newman, que proviene de la tradición inglesa de la filosofía, a juicio de Kasper, parte de la idea de que "el cristianismo se divide necesariamente en sus distintos aspectos al ser apropiado subjetivamente en la fe de la Iglesia", y añade que esta "idea se deja 'sonsacar' distintos aspectos en las distintas épocas de acuerdo con sus características, y se asimilan así los datos históricos, naturalmente, manteniendo siempre el tipo del todo" (Ídem). Finalmente, Kasper habla de "otras teorías", en las que incluye a autores como H. de Lubac, Urs von Balthasar y Karl Rahner. Estos autores, partiendo del hecho de que "la revelación no consiste primeramente en la comunicación de una suma de proposiciones, sino en la autocomunicación de Dios por Jesucristo en el Espíritu Santo", dirán que "la Iglesia tiene de esto una conciencia global, cuyo desarrollo no debe entenderse de un modo puramente lógico, sino que ha de interpretarse también en el contexto de la acción del Espíritu, de los dones del Espíritu, del sentido de la fe inspirado por el Espíritu” (Ídem).

b) Beinert, por su parte, habla de "distintas teorías para explicar el fenómeno” de la evolución del dogma; y considera que las más importantes han sido las siguientes. En primer lugar, la propuesta de "la teología neoescolástica", para la que "la evolución dogmática es un proceso deductivo en el que se efectúa un progreso cognitivo lógico pasando de lo confuso a lo claro" ${ }^{47}$, y menciona expresamente a autores como R. M. Schultes, F. Marín-Solá, y M. Tuyaerts, que expusieron sus ideas en libros publicados durante el primer cuarto del siglo XX. La segunda teoría sería la de J. H. Newman, "para quien la evolución dogmática es el resultado de un "sentido ilativo" (illative sense)", por el que en una decisión personal se reconoce la validez de un conocimiento. La tercera teoría es la de M. Blondel, quien entiende la evolución como "un proceso en el que se transmite y de nuevo se pone en práctica una realidad experimentada en la vida cristiana". Finalmente habla de la teoría de $\mathrm{H}$. de Lubac y H. Urs von Balthasar, para quienes "la evolución dogmática es el desarrollo de la global conciencia creyente de los cristianos, operado por el Espíritu” (Ídem).

c) La exposición de Tamayo, en cambio, es más imprecisa. De hecho no habla tanto de teorías, sino sólo de tres grandes respuestas al 
problema de la articulación entre revelación, dogma y evolución de los dogmas. La primera respuesta es la que denomina "el planteamiento histórico". No aclara, sin embargo, quienes serían sus principales representantes. En todo caso, dirá que para los representantes de esta respuesta "las investigaciones históricas muestran la existencia de una identidad fundamental de las verdades de fe en las diferentes etapas de la conciencia eclesial", por lo que tienden a concluir que "los dogmas que han sido definidos por el magisterio de la Iglesia a lo largo de los siglos eran ya conocidos y admitidos, de una u otra forma, en la época apostólica" ${ }^{46}$. El segundo planteamiento de que nos habla Tamayo es el "lógico-intelectualista", desarrollado por neoescolásticos como F. Marín-Solá, R. M. Schultes y M. Tuyaerts, ya citados por Kasper. Para Tamayo, estos autores tienden a reducir "la evolución de los dogmas a una cuestión puramente lógica y apela al valor dogmático de las conclusiones teológicas" (Ídem). Por lo tanto, concluyen que "los dogmas definidos por la Iglesia, tanto los antiguos como los más recientes, no aportan novedad alguna sobre la doctrina de la Escritura, sino que son deducciones lógicas de la doctrina revelada" (Ídem). Por último habla del planteamiento teológico, "en puntos importantes", enlaza con las teorías de la escuela de Tubinga, del cardenal Newman y de Blondel. Este planteamiento parece estar representado por autores más modernos como Schillebeecks y Rahner. Para estos autores, el modelo de desarrollo dogmático no es el "orgánico de la bellota" que llega a convertirse en árbol; no se trata por tanto de "un proceso tranquilo y sosegado, ni se reduce a un crecimiento armónico o a un autodesenvolvimiento idílico, sino que está jalonado, la mayoría de las veces, por confrontaciones y tensiones, dentro y fuera de la Iglesia, de carácter teórico y práctico" (Ídem., p. 340).

d) Finalmente, Mansini habla de cuatro "teorías de la evolución". La primera desarrollada al parecer por Wilhelm Bousset (1865-1920), quien entendió la evolución como "reafirmación o afirmación más clara de lo que ya se posee y conoce conceptualmente" ${ }^{49}$. La segunda teoría sería nuevamente la de Marín-Solá (o neoescolástica), quien entiende la evolución "como la actividad lógica de sacar conclusiones a partir de premisas reveladas", por lo que concluye que "sería posible, desde un punto de vista estrictamente lógico, demostrar la continuidad del dogma con la Escritura" (Ídem).

La tercera estaría representada por Schleiermacher y el modernismo, quienes entienden la evolución "como la transformación material de la 
expresión didáctica de la fe según el pensamiento científico y filosófico de la época" (Ídem, p. 344). Por último habla de la perspectiva asumida por autores como Newman, Moler y Blondel, quienes entienden la evolución como "contemplación propiamente teológica de la realidad revelada por una razón necesariamente condicionada por la historia e iluminada por la fe" (Ídem).

Quisiera hacer a continuación un balance de todas estas teorías para establecer con más claridad cuáles han sido las más importantes hasta el momento.

\subsection{Síntesis de las principales teorías sobre el problema de la evo- lución del dogma}

Lo primero que llama la atención al intentar hacer la síntesis de la exposición de todos estos autores es la cantidad de nombres que aparecen. Se llega a mencionar hasta ocho autores y escuelas: Marín-Solá, Blondel, la Escuela de Tubinga, Newman, de Lubac, Urs von Balthasar, Rahner, Wilhelm Bousset, Schleiermacher, Moler. Por supuesto, no podemos entrar a profundizar en cada uno de estos autores, sino que me voy a centrar en las escuelas o autores que simplemente son más mencionados. Haciendo, pues, un balance meramente numérico, se destacan en primer lugar las posturas de los neoescolásticos con autores como Marín-Solá (1873-1932) a la cabeza. El segundo personaje más mencionado es Maurice Blondel (1861-1949). En tercer lugar, se menciona a la Escuela protestante de Tubinga. En cuarto lugar, Newman (1801-1890). Y en quinto lugar, el pensamiento de autores más contemporáneos como de Lubac, Balthasar y Rahner.

Debo admitir, por otro lado, que las exposiciones de Kasper, Tamayo, Beinert y Mansini son tan concisas que resulta prácticamente imposible dejar en claro en qué consiste cada una. Además, no existe un acuerdo universal sobre dónde ubicar a cada uno de estos grandes autores. Todo ello hace, pues, que la comprensión de las diferentes posturas sea bastante difícil, y mucho más el intentar presentar sus rasgos principales. Por ello, en la medida de lo posible trataré de ir complementando en qué consisten las ideas principales de cada uno de estos autores o tradiciones, con excepción de las posturas de Rahner, Lubac y Balthasar; dado lo complejo de cada una de sus propuestas, me sería muy difícil resumir sus posturas en este trabajo. En lugar de ello, y como representantes de las posturas teológicas más actuales, haré la presentación de las teorías de Torres Queiruga y Zubiri. 


\section{a) John Henry Newman (1801-1890)}

No cabe duda de que el pensamiento del Cardenal Newman marcó un hito importante en la reflexión sobre la evolución de los dogmas. Sus ideas fueron expuestas en su libro Essay on the Development of Chirstian Doctrine, redactado originalmente entre 1843 y 1845. A continuación transcribo una parte de la Introducción de este importante libro suyo en el que parece resumir las tesis fundamentales de su teoría.

El crecimiento y la expansión del credo y del ritual cristiano, y las variaciones que han acompañado el proceso en el caso de escritores e Iglesias individuales, son los fenómenos que necesariamente acompañan a cualquier filosofía o forma de gobierno que vaya al fondo del intelecto y del corazón, y que haya tenido un predominio largo o extenso. Por la naturaleza de la mente humana, es necesario el tiempo para comprender plenamente y llevar a la perfección las grandes ideas. Las verdades más sublimes y extraordinarias, aunque hayan sido comunicadas al mundo de una vez por todas por maestros inspirados, no pueden comprenderse por sus destinatarios de una sola vez, sino que, al haber sido recibidas y transmitidas por mentes no inspiradas y a través de medios humanos, requieren más tiempo y una meditación más profunda para su completa dilucidación. Esto se puede llamar la teoría del desarrollo de la doctri$n a^{50}$.

Da la impresión que para Newman la evolución de los dogmas debe entenderse de una manera un tanto orgánica. Se trata por tanto de una teoría montada sobre una visión bastante greco-naturalista de la realidad y de la evolución. Se equivocan por tanto, los que ven en Newman un adelanto de las teorías evolutivas de Darwin. En todo caso, para Newman la evolución de los dogmas debe entenderse como una especie de crecimiento que permite ir descubriendo sólo con el paso del tiempo aquellas partes de la "semilla" (revelación inicial) que por su misma "naturaleza" no era posible descubrir más que con el paso del tiempo. Las nuevas definiciones dogmáticas vendrían siendo algo así como las hojas del árbol que aunque definitivamente estaban de algún modo contenidas en la semilla, no pueden apreciarse más que con el paso del tiempo, cuando la semilla haya comenzado su desarrollo o el despliegue de sus potencialidades.

\section{b) La Escuela de Tubinga}

Las contribuciones de la Escuela protestante de Tubinga sobre el 
tema del dogma dieron inicio con los escritos de Ferdinand Christian Baur (1792-1860), quien, entre 1838 y 1847, publicó una serie de libros sobre algunos dogmas cristianos, como la Trinidad (1838) y la Encarnación (1841-1843), por lo que se le considera como "el pionero" en el estudio de la historia de los dogmas, y para tal fin aplicó las categorías de la filosofía de la historia de Hegel ${ }^{51}$. Otro importante autor asociado a la Escuela de Tubinga, discípulo de Baur, y que de igual manera intentó aplicar las teorías filosóficas de Hegel al problema del dogma, fue David Strauss (1808-1874), quien en 1840 publicó su libro La doctrina de la fe cristiana, su desarrollo doctrinal y conflicto con la ciencia moderna ${ }^{52}$.

La evolución de los dogmas, desde la perspectiva de los teólogos de Tubinga, se entiende entonces no como algo estrictamente orgánico, como parece ser la postura de Newman, sino como resultado de la dialéctica histórica, de la controversia (tesis-antítesis-síntesis), de "los movimientos reales de la historia humana”, como puntualiza Tamayo ${ }^{53}$. Sin embargo, no entienden la aparición de nuevos dogmas como una estricta novedad, pues los contenidos de la revelación siguen siendo los mismos, sólo cambian "las expresiones, formas y conceptos". Zubiri, resumiendo el aporte de Baur a la comprensión de la evolución de los dogmas, y destacando la gran influencia hegeliana en su concepción, nos dice lo siguiente:

La historia de los dogmas, desde el punto de vista actual, es el enfrentamiento del Cristianismo con la historia teologal entera como un todo. Para unos, Dios en su historia ha muerto: fue la frase de Nietzsche. Para otros, como para Hegel, Dios vive. La vida de Dios consiste en que Dios se va haciendo, va llegando a ser. Es un devenir en sí. En este caso, la historicidad del Cristianismo como un devenir del mismo Dios sería pura y simplemente la razón absoluta, la idea, que se va plasmando en conceptos finitos a lo largo de la historia. Fue, por ejemplo, el método que introdujo en la historia de los dogmas F. Ch. Baur, precisamente en Tubinga ${ }^{54}$.

Por todo lo anterior, parece justa la opinión de los especialistas que enfatizan que la postura de los teólogos de Tubinga es muy similar a la de Newman. Lo único que cambia es el mecanismo de la evolución: en Newman es más natural-aristotélico (paso natural de la potencia al acto), y en los teólogos de Tubinga es más histórico-hegeliano (dialéctica), pero siempre a mi juicio sería una concepción naturalista (paso de la potencia al acto pero por la dialéctica histórica). 
Aquí se plantea en todo caso el desafío de si es posible entender esta evolución en términos que van más allá de la concepción greco-naturalista de la realidad, de la que al final parten como presupuesto metafísico último, aunque no suficientemente discutido, tanto Newman como los teólogos de Tubinga. Quizá en esto estriba la novedad que introdujo las teorías de Blondel.

\section{c) Maurice Blondel (1861-1949)}

Blondel desarrolló su teoría sobre el dogma en sus escritos Carta sobre las exigencias del pensamiento contemporáneo en materia de apologética (1896) y en su Historia y dogma (1903). Para Blondel, los dogmas no son producto de una evolución lógica, sino histórica; por tanto no son resultado de una evolución "necesaria", sino "contingente" 55 . Por ello, postula que los dogmas deben de estar abiertos a la reinterpretación a la luz de las distintas situaciones históricas en que son leídos, enseñados y creídos. Esto, como se examinó, es precisamente lo que rechazó el concilio Vaticano I, y se ha tenido la oportunidad también de comprobar que la Iglesia católica sigue manteniendo este rechazo hasta el presente. Ahora bien, el descubrimiento de lo histórico como categoría que va más allá de lo natural para la comprensión de la constitución de los dogmas, parece ser el aporte fundamental de Blondel a esta discusión ${ }^{56}$.

\section{d) La tradición neoescolástica o neotomista}

Ya se ha dicho que esta tradición está representada por autores como F. Marín-Solá, R. M. Schultes y M. Tuyaerts. Pero quien llegó a convertirse en su representante principal fue sin duda Marín-Solá, con su libro La evolución homogénea del dogma católico, publicado en 1923.

En términos generales para estos autores, la evolución dogmática debe entenderse meramente como un proceso deductivo-lógico, como "una deducción puramente lógica" que permite pasar como dice Beinert de lo confuso a lo claro, pero en ningún momento se habla de una novedad estrictamente tal. Como insiste Tamayo, esta tradición sostiene que los dogmas definidos por la Iglesia, tanto los antiguos como los más recientes, "no aportan novedad alguna" a la doctrina contenida en la revelación, sino que son precisamente "deducciones lógicas de la doctrina revelada”. Torres Queiruga califica a esta postura de “ahistórica” y "logicista" (Torres Queiruga, p. 242), y la mayoría de los autores consultados coinciden en que se trata de una teoría ya abandonada, aunque sin duda ha sido asumida como oficial por parte de la Iglesia católica. 
En lo que sigue, quisiera presentar las posturas básicas de Andrés Torres Queiruga y de Xavier Zubiri respecto de los temas desarrollados en las páginas anteriores. Esto permitirá confirmar que aunque si bien es cierto que no existe una única manera de afrontar los problemas del dogma y su evolución, sí es posible siempre acercarse a ellos con perspectivas nuevas y más dialogantes. Quizás ésta sea el punto más importante a destacar, la lección a no olvidar.

\section{Los aportes de Andrés Torres Queiruga y Xavier Zubiri al problema del dogma y su evolución}

Dadas las limitaciones de espacio, es imposible hacer una exposición completa de las posturas de Torres Queiruga y de Zubiri. En consecuencia, voy a destacar únicamente las líneas de fuerza principales de sus respectivas argumentaciones.

Ante todo, hay que decir que tanto en Zubiri como en Torres Queiruga es central la discusión de las tesis modernistas y protestantes, y que tratan de responder a sus críticas, pero quieren hacerlo desde una perspectiva mucho más dialogante. No las descalifican de entrada, sino que buscan comprender lo esencial de sus respectivos planteamientos, puesto que consideran que sus señalamientos tienen algún fundamento. Pero hay que decir, al mismo tiempo, que ambos autores señalan con bastante claridad las limitaciones que contienen las posturas protestantes y modernistas, y esbozan así una respuesta racional a los cuestionamientos establecidos por ambas corrientes teológicas desde una perspectiva que, no obstante todo, quiere permanecer fiel a la esencial de la postura católica.

\subsection{Defensa "racional” de los dogmas y del Magisterio}

En mi opinión, tanto Zubiri como Torres Queiruga quieren construir una especie de teología fundamental del dogma católico y de su evolución. Es claro que quieren defender la postura de que los dogmas y el Magisterio son parte esencial del modo cristiano de ser católicoromano, y no representan necesariamente, en sí mismos, una corrupción del Evangelio o de la Iglesia. Ninguno de los dos autores niega, pues, el carácter absoluto y universal de los dogmas ni el papel fundamental que tiene que jugar el Magisterio en la constitución de los dogmas. Pero no se trata, hay que aclarar inmediatamente, de una defensa a ultranza o ultramontana, porque tampoco mantienen una postura sumisa ante la 
doctrina oficial de la Iglesia, sino que le hacen importantes correcciones.

Por poner un ejemplo, ambos autores enfatizan taxativamente el carácter histórico de los dogmas. De hecho, uno de los objetivos fundamentales de Torres Queiruga es mostrar que se puede conjugar tanto la absolutez como la relatividad de los dogmas, sin caer en una contradicción apriorística de términos que haga por tanto absurda la existencia de los dogmas. Para ello hará uso del concepto de "nocional teológico" desarrollado por Amor Ruibal. Sin entrar en mayores disquisiciones, su tesis fundamental es la siguiente:

De modo muy sucinto y radical, apoyándonos en los análisis de la noción en general, pueden hacerse dos afirmaciones fundamentales: 1) queda asegurada la absolutez y validez real de toda expresión dogmática, pues ella contiene, como un momento suyo esencial, esa totalidad primigenia; 2) pero, al mismo tiempo, queda subrayada la relatividad e insuficiencia de toda expresión dogmática concreta, pues sólo a su modo, desde su perspectiva, en su grado de explicitación, puede contener aquella totalidad ${ }^{57}$.

También Zubiri hace importantes aportaciones que buscan reafirmar el carácter histórico de los dogmas y su interpretación, sin caer por ello en el temible y terrible "relativismo" o pretender la disolución de la Verdad cristiana.

La definición (dogmática) define el cumplimiento de una posibilidad de intelección en el depósito revelado. El dogma está fundacional $y$ fundadamente en el depósito revelado. Y precisamente porque cada definición dogmática es el cumplimiento de una posibilidad, la revelación en sus definiciones dogmáticas es intrínseca y formalmente histórica. El dogma está en la fundamentalidad histórica y además incoativa de la revelación ${ }^{58}$.

En definitiva, para Zubiri, los dogmas son esenciales a la vida de la Iglesia porque a través de ellos "se hace más presente" o se "actualiza" el contenido de la revelación, sin que ello implique una modificación o deformación de la misma, tal como sostuvieron los protestantes y los modernistas. Así, el concepto zubiriano de "actualización” no hace más que explicar cómo se realiza o en qué se fundamenta la continuidad entre revelación y dogma. 
Sin embargo, ambos autores señalan la necesidad de cambiar el perfil del Magisterio, para superar lo que Torres Queiruga ha denominado, siguiendo a Tillich, "la esterilidad dogmática de la teología católica-romana" o la "esclerotización formalista del planteamiento católico"bg. Tanto Torres Queiruga como Zubiri aceptan esta crítica al Magisterio, porque en no pocas ocasiones esta instancia ha jugado un papel represivo frente a la diversidad o ha asumido un papel poco dialogante. Zubiri recuerda en esta línea el "lamentable episodio de Galileo", al que considera un "choque penoso y brutal, por parte de cardenales incomprensivos" pero no tanto, y esto es fundamental, "una condenación dogmática” o magisterial ${ }^{60}$.

El lamentable episodio de Galileo es el conflicto de dos mentalidades, pero no el conflicto de la revelación con la ciencia. Esto sería absurdo. La mentalidad medieval chocó con la mentalidad moderna y la condenó; pero no fue una condenación dogmática, sino meramente curial. La razón científica no es religiosa, pero tampoco es irreligiosa. Es solamente $\operatorname{arreligios}^{61}$.

De hechos lamentables como estos, no concluyen ambos autores que el Magisterio deba desaparecer; por el contrario, consideran que tiene un papel fundamental que cumplir en la vida de la Iglesia, precisamente en la constitución de los dogmas, asegurando la continuidad entre revelación original e interpretación de esa revelación. Lo importante es que se debe asegurar esa continuidad respetando el pluralismo y la apertura que caracterizan a las sociedades modernas.

No la anulación de la riqueza ni la arbitraria nivelación de la variedad, sino la garantía contra la dispersión o la corrupción, la posibilidad de ser acordada en la sinfonía plural y unánime de una sola confesión ${ }^{62}$.

Zubiri por su parte insiste en que la infalibilidad dogmática no debe ser entendida como un privilegio exclusivo de una parte de la Iglesia, ni como "una especie de guillotina que cae sobre la historia de la revelación"63. Más bien, la infalibilidad debe recaer formalmente sobre todo el Cuerpo Místico de Cristo, a cuya cabeza está Cristo y no el Papa. Así, la infalibilidad del Magisterio (la "infalibilidad de docencia") debe estar basada y sustentada en última instancia en "la infalibilidad de creencia", que sería la propia de "el cuerpo entero de la Iglesia, tomado históricamente" ${ }^{64}$ : 
Ahora bien, uno puede preguntarse cómo se llega a esta definición (dogmática). A ella se llega precisamente por aquello que constituye la presencia de Cristo en el seno de la Iglesia: el Espíritu de la Verdad. Por eso decía antes que hay una infalibilidad de creencia (infallibilitas credendi) en el cuerpo entero de la Iglesia, tomado históricamente. En algunos jerarcas suyos hay la infallibilitas docendi, pero la verdad es que esta segunda infalibilidad está otorgada y es real en tanto en cuanto forma parte de la primera. No son dos infalibilidades distintas. Pensar que un concilio ecuménico recibe su infalibilidad del Papa es quimérico. No sería infalible sin el Papa, pero no lo es por el Papa. Esto fue un conciliarismo de mala especie: creer que la Iglesia es el Papa, los cardenales y los obispos; y que los demás nos acercamos a ella ${ }^{65}$.

\subsection{Limitaciones de los planteamientos modernistas y protestantes}

Pero quizás es más importante, a mi juicio, que Zubiri y Torres Queiruga defiendan la postura básica del catolicismo porque consideran que las críticas modernistas y protestantes no son lo suficientemente convincentes como para aceptar sus conclusiones sin discusión. Así Torres Queiruga se ha esforzado por mostrar que el argumento de la "sola Escritura" esgrimido por los protestantes no basta para concluir la irrelevancia del Magisterio:

Pero también es verdad que el ejemplo de nuestros hermanos evangélicos nos hace ver que, si estos peligros son reales ${ }^{66}$, no lo es menos la casi total imposibilidad de encontrar sin ella el Evangelio único —aun reducido a la sola medida necesaria e indispensable - bajo la letra múltiple de la Escritura. Entonces se corre siempre el peligro de que cada teólogo o cada escuela tienda a empezar siempre ab ovo y a forzar una unanimidad $\operatorname{artificiosa}^{67}$.

Por su parte, Zubiri considera que los modernistas, influidos en gran medida por los protestantes, llegaron a concluir que la relación que existe entre revelación y dogma podría compararse con una especie de "impulso" (revelación) que genera a lo largo del tiempo una "onda" que se va cristalizando externamente en "símbolos" (dogmas). Pues bien, para Zubiri esta imagen y concepción resulta absolutamente inaceptable. De hecho, la califica esta interpretación como "la más falsa", basándose precisamente en la necesidad de concebir la revelación como un "depósito": 
Este simbolismo externo fue defendido a principio de siglo por lo que se llamó, probablemente con poca fortuna, el modernismo. Ahora bien, la Iglesia rechazó este punto de vista por imposible dentro de lo que es el Cristianismo. Porque la revelación no es un "impulso", sino que es un "depósito" de verdad. Todo lo histórico que se quiera, pero un depósito de verdad ${ }^{68}$.

Claro que Zubiri dedica bastantes páginas a explicar qué entiende por "depósito", y es claro que también se distancia de la manera tradicional de concebir el depósito y la relación que deben mantener los fieles respecto de ese depósito. Si se recuerda, esta manera "tradicional" de concebir el "depósito" quedó caracterizada, y un tanto caricaturizada, de la siguiente manera:

El depositum... no es algo que se han imaginado los hombres, sino cosa que han recibido (de Dios); no es algo que ellos han compuesto (inventum), sino cosa que a ellos les ha sido confiada (por Dios); una cosa, por consiguiente, que no es fruto de la ingeniosidad humana, sino de la enseñanza (recibida); no de uso privado, arbitrario (privatae usurpationis), sino tradición pública (es decir, que a todos obliga); una cosa no extraída de ti, sino traída a ti..., donde tú no eres autor, sino custodio; no maestro, sino discípulo; no guía, sino discípulo ${ }^{69}$.

En ningún momento Zubiri sostiene que sea necesario entender el depósito como una especie de verdad bajada del cielo, puesto que es el ser humano histórico y concreto quien se ha topado "con" y ha alumbrado las distintas posibilidades de intelección de lo que se define como dogma. Por supuesto que no niega Zubiri la participación del Espíritu Santo en todo este proceso, pero tampoco reduce el papel del Magisterio y del creyente a ser un mero instrumento del Espíritu Santo.

En un primer estado tenemos el depósito revelado integral. El cual tiene unas verdades expresas y además unas verdades incoadas... (En segundo lugar), al hombre se le alumbran ante esta incoación, en una situación perfectamente concreta, determinadas posibilidades. Ahora bien, esta situación es una situación integral, es la situación religiosa integral del hombre... (En tercer lugar), de estas posibilidades una es la verdadera. Las otras no son verdaderas. La que es verdadera es justamente la que se cumple, y es el término de una definición dogmática ${ }^{70}$. 
Como se puede observar, tanto Zubiri como Torres Queiruga desarrollan un diálogo bastante complejo entre la postura católica y la protestante-modernista.

\subsection{Limitación fundamental del planteamiento católico}

Pero yendo al fondo último de toda esta cuestión, a mi juicio, ambos autores van a mostrar que en gran parte las críticas protestantes y modernistas se justifican en la medida en que la Iglesia se aferra a una interpretación demasiado estrecha tanto del dogma como de la evolución de los mismos.

En lo que respecta al dogma, esta concepción estrecha fue establecida por el concilio Vaticano I, precisamente en el clímax del enfrentamiento de la Iglesia con el mundo liberal. Este dato histórico no puede simplemente obviarse a la hora de entender la definición de dogma que la Iglesia asumió como oficial; y como ya se explicó también, desde el concilio Vaticano I y desde la teología tomista, la revelación ha sido entendida como una especie de dictado divino de verdades intemporales, y los dogmas como un cuerpo de verdades de fe inmutables; mucho más inmutable que la misma revelación, puesto que son definidos, según esta interpretación, infaliblemente para todos los tiempos y culturas. En ese sentido, no pueden ser interpretados más que desde la perspectiva hermenéutica-filosófica con que fueron formulados originalmente, so pena de excomunión. Se tuvo la oportunidad de examinar la diversidad de significados que el concepto de dogma tuvo o adquirió a lo largo de su historia, significados que se fueron perdiendo poco a poco al calor de las luchas contra el protestantismo y el liberalismo.

Por su parte, Torres Queiruga resume en los siguientes aspectos las principales pérdidas que el concepto o la noción de dogma sufrió a partir del concilio Vaticano I:

1) La pérdida del sentido de la totalidad, al trasladar el centro de gravitación a las fórmulas aisladas; 2) la acentuación del carácter formaljurídico frente al material-teológico, es decir, la excesiva acentuación del valor de la definición eclesial frente a la estructura misma del contenido de la fe, ordenado a la visión (que era todavía la concepción medieval); 3) la evidente debilitación del sentido cultual y de confesión que revestía el dogma en la época patrística y todavía hoy en la tradición oriental ${ }^{71}$.

El segundo problema de fondo estriba en que la Iglesia ha terminado por asumir como suya, como doctrina oficial casi incuestionable, la in- 
terpretación escolástica o neotomista de la evolución de los dogmas. Si se recuerda, el principal representante de esta corriente neotomista fue Marín-Solá, para quien la evolución del dogma se debe entender, según la interpretación de Zubiri, como el paso de lo implícito a lo explícito (es decir, como una especie de paso de la potencia al acto) por vía exclusiva de la deducción o el razonamiento lógico.

Los teólogos en general han pensado ante todo y sobre todo en lo que llaman la conclusión teológica, deducida de las premisas de un razonamiento. Las dos pueden ser dogmáticas, caso en el cual tendremos un tercer dogma, consecuencia de los anteriores $^{72}$.

A este respecto, también ha mostrado Torres Queiruga el trasfondo político-religioso (defensa frente al protestantismo) de esta "cerrazón" a considerar desde otras perspectivas la evolución dogmática:

... el problema de la evolución del dogma se entiende muchas veces -hasta hace pocos años prácticamente siempre- como el problema de la aparición de nuevos dogmas. Tal es, en efecto, el fondo del planteamiento heredado de la escolástica post-tridentina -defensa, frente al protestantismo, de la aparición de "nuevos" dogmas- y tal ha sido en gran medida el trasfondo de la reviviscencia de la problemática, a propósito de la proclamación de los “nuevos” dogmas marianos ${ }^{73}$.

\subsection{Hacia una superación de las limitaciones del planteamiento católico}

Es en este contexto que se entiende que tanto para Zubiri y como para Torres Queiruga, la solución definitiva a las críticas modernistas y protestantes pasa, al menos, por dos fases. En primer lugar, implica un distanciamiento importante de la postura neotomista o tradicional; en otras palabras, no se puede aceptar sin discusión que se trata de la única manera de concebir los dogmas y su evolución. En la siguiente cita se puede observar claramente el distanciamiento de Zubiri respecto de esta postura tradicional:

La cosa es bien clara, por ejemplo, en el caso de la Inmaculada Concepción. Los teólogos tomistas pretendían encerrar en un silogismo la definición de este dogma... En fin, con posterioridad se puede poner en silogismo todo, hasta el estar leyendo estas páginas. Pero esto no quiere decir que fuera el camino por 
el que se descubrió. Los grandes maestros de la teología especulativa no admitieron la Inmaculada Concepción. En cambio, unos pobres franciscanos sintieron la devoción a la santísima Virgen en forma de Inmaculada Concepción. Y allí es donde estaba la verdad del depósito revelado ${ }^{74}$.

En segundo lugar, la superación de las críticas pasa por la adopción de nuevas perspectivas de interpretación, de nuevas hermenéuticas, que es lo expresamente prohibido por el concilio Vaticano I so pena de excomunión. Pero, como haciendo caso omiso a esa prohibición, ambos autores ensayan aplicar sus respectivas posturas filosóficas a la interpretación tanto de la revelación, como del dogma y su evolución. Zubiri anuncia así su deseo de aplicar nuevas hermenéuticas a la problemática del dogma:

Estas observaciones no invalidan la obra de los teólogos de la conclusión $^{75}$. Pero sí invitan a hacer -por lo menos modestamente- algunas reflexiones para atender más estrictamente a lo que es la historia de la revelación ${ }^{76}$.

Y Torres Queiruga lo hace de la siguiente manera:

... se ha creado una situación que pone a la teología frente a una nueva tarea decisiva: nada menos que la de darse a sí misma una nueva fundamentación filosófica... La teología tiene que integrar dentro de sí el nuevo talante del conocimiento moderno. Tarea amplia, complicada y nada fácil, para la que resulta ante todo impensable "elaborar un tratado del conocimiento conforme a la epistemología moderna y que podría servir al proyecto del conocimiento teológico" ${ }^{\prime 7}$.

Imposible entrar aquí en los detalles concretos de cada una de las propuestas de ambos autores; pero lo importante era mostrar que siguen habiendo caminos novedosos para enfrentar problemas tan tradicionales como los dogmáticos; y esto resulta decisivo, en tiempos como estos, en los que parecen ya lejanas las controversias generadas por los teólogos de la liberación, en los que parece se está recuperando la "cordura” y la "serenidad", cuando finalmente parece que se está regresando a una visión estable de la Iglesia, sobre su misión y función en este mundo -innegablemente social y político-.

Dado, pues, un creciente proceso de involución eclesial y teológica, creo que no resulta del todo superfluo recordar, al menos, que la ma-

\section{7}


yoría de las posturas oficiales respecto de los dogmas son producto de decisiones históricas y políticas. Ciertamente, resulta difícil de creer hoy que temas como el dogma o la evolución dogmática generaron gran controversia y plantearon graves desafíos a una Iglesia demasiado acomodada al poder y a la posesión de una verdad supuestamente dada directamente por Dios desde el inicio de su caminar por este mundo.

En definitiva, fácilmente se olvida que lo que ahora se considera doctrina oficial fue resultado de la imposición más que de un consenso, fue más bien resultado de destruir la diversidad teológica que de promoverla; fácilmente se olvida que si en la actualidad no se sigue discutiendo sobre temas como el dogma y la evolución dogmática con la misma energía con que se hizo en los años 60 y 70 del siglo pasado, no es porque se hayan convertido en cuestiones irrelevantes para un mundo moderno como el nuestro, sino más bien porque existe una especie de autocensura entre los mismos teólogos, quizás porque ya nadie quiera volver a abrir heridas pasadas que probaron ser muy dolorosas.

\section{NOTAS}

1 En el caso de Torres Queiruga, desarrollaré parte de sus reflexiones expuestas en el libro, Constitución y evolución del dogma: La teoría de Amor Ruibal y su aportación, Ediciones Maroya, S. L., Madrid, 1977.

2 En el caso de Xavier Zubiri, recurriré a algunas porciones de dos de sus libros póstumos, El problema filosófico de la historia de las religiones, Alianza EditorialFundación Xavier Zubiri, Madrid, 1993; y El problema teologal del hombre: Cristianismo, Alianza Editorial-Fundación Xavier Zubiri, Madrid, 1997.

3 G. F. Mansini, “Dogma”, en R. Latourelle y R. Fisichella (eds), Diccionario de teología fundamental, Madrid, 1992, pp. 338-349; p. 341.

$4 \quad$ H. Denzinger y P. Hünermann, El magisterio de la Iglesia: Enchiridion, symbolorum, definitionum et declarationum de rebus fidei et morum, Herder, Barcelona, 1999.

5 D. Bonifazi, "Dogma”, en L. Pacomio y otros, Diccionario teológico interdisciplinar, Vol II, ediciones Sígueme, Salamanca, 1982, p. 280.

$6 \quad$ W. Beinert, “Dogma y declaración dogmática”, en W. Beinert (ed), Diccionario de teología dogmática, Herder, Barcelona, 1990, pp. 219-222; p. 219.

7 W. Kasper, “Dogma-Evolución de los dogmas”, en P. Eicher (ed), Diccionario de conceptos teológicos (I), Herder, Barcelona, 1988, pp. 262-275, pp. 268-269.

8 J. J. Tamayo, "Dogma”, en C. Floristán y J. J. Tamayo (eds), Conceptos fundamentales del cristianismo, Trotta, Madrid, 1993, pp. 331-344, p. 331. 
Cf. DS 125,150

Cf. DS 125, 150, 800, 805, 851, 1331, 4522, 4780

Cf. DS, 251, 2800-2801, 2803-2804, 3903, 4173, 4177-4179

Cf. DS, 3074-3075, 4150

J. R. Geiselmann, "Dogma”, en Conceptos fundamentales de teología I, citado por Tamayo, p. 332.

D. Bonifazi, p. 281.

A. Torres Queiruga, p. 362.

W. Kasper, p. 272.

H. Kung, La Iglesia, Barcelona, 1970.

H. Kung, ¿Infalible? Una interpelación, Barcelona, 1972.

D. Bonifazi, p. 286.

J. J. Tamayo, p. 334. Los énfasis son míos.

G. F. Mansini, p. 341. Los subrayados son míos.

J. J. Tamayo, p. 333.

Cf., J. Noemi, "Sobre la credibilidad del dogma cristiano", en Teología y vida, 2-3 (2004) 258-272. Pontificia Universidad Católica de Chile, p. 261, nota 36.

Vicente de Lérins, Commonitorium primun, 23, n. 3, citado en DS, 3020.

J. J. Tamayo, p. 332.

W. Kasper, pp. 263-264; los subrayados son míos.

Tomado del "Santoral” de la página de la Arquidiócesis de Mérida-Badajoz, España, http://www.archimeridabadajoz.org/santoral/mayo.htm\#DÍA\%2024; los énfasis son míos.

http://www.mercaba.org/SANTORAL/Vida/05/05-24_S_vicente_de_lerins.htm. “San Vicente de Lérins”, en la versión española de la Enciclopedia católica en http:// www.enciclopediacatolica.com/v/vicentelerins.htm.

Cf., "St. Vincet of Lerins", en Catholic Encyclopedia, http://www.newadvent. org/cathen/15439b.htm.

Debo confesar que me he esforzado por establecer la fecha de canonización de tan peculiar santo, pero me ha sido prácticamente imposible encontrarla. Sin embargo, no me sorprendería comprobar que su beatificación y canonización se realizó muy probablemente por el mismo Benedicto XIV, es decir cuando sus ideas se convirtieron en armas muy efectivas en contra de la teología de los Protestantes. Esta es una hipótesis que queda sujeta a comprobación.

J. J. Tamayo, p. 333.

W. Kasper, p. 262. 
W. Kasper, p. 263.

J. J. Tamayo, p. 332.

G. F. Mansini, p. 342.

J. J. Tamayo, p. 333.

J. J. Tamayo, p. 333.

A. Torres Queiruga, pp. 358-359.

W. Beinert, p. 279.

J. J. Tamayo, p. 336.

J. J. Tamayo, p. 336.

A. Torres Queiruga, p. 359; los subrayados son míos.

A. Torres Queiruga, p. 282.

W. Beinert, p. 279.

W. Kasper, p. 272.

W. Beinert, p. 279.

J. J. Tamayo, p. 337.

G. F. Mansini, p. 343.

Tomado de D. I. Grézes, "John Henry Newman, profeta de la verdad católica”, en http://feyrazon.org/newman.htm.

Cf. J. Haussleiter, "Baur, Ferdinand Christian, and the later Tubingen School”, en http://www.ccel.org/s/schaff/encyc/encyc02/htm/iv.iv.xx.htm.

También puede consultarse, "Ferdinand Christian Baur", en LoveToKnow 1911 Online Encyclopedia. (C) 2003, 2004 LoveToKnow, en http://89.1911encyclopedia. org/B/BA/BAUR_FERDINAND_CHRISTIAN.htm.

2 Cf. J. H. Kim, "David Friedrich Strauss (1808-1874)", The Boston Collaborative Encyclopedia of Modern Western Theology, en http://people.bu.edu/wwildman/ WeirdWildWeb/courses/mwt/dictionary/mwt_themes_475_strauss.htm\#top.

J. J. Tamayo, pp. 338-339.

X. Zubiri, "Historia del dogma”, en El problema teologal del hombre: cristianismo, pp. 484-485.

Cf., "Maurice Blondel (1861-1949)" en The Internet Encyclopedia of Philosophy, en http://www.iep.utm.edu/b/blondel.htm.

Esto último queda, sin embargo, como una hipótesis que necesita ser más analizada.

A. Torres Queiruga, p. 308; los subrayados son míos.

X. Zubiri, "El Cristianismo y la razón moderna", en El problema filosófico de la historia de las religiones, pp. 316-317; los subrayados son míos. 
A. Torres Queiruga, pp. 263 y 264.

X. Zubiri, "El Cristianismo y la razón griega", en El problema filosófico de la bistoria de las religiones p. 278.

Ídem.; los énfasis son míos.

A. Torres Queiruga, p. 276.

X. Zubiri, "Historia del dogma", en El problema teologal del hombre: Cristianismo, p. 482.

Ídem, pp. 481-482.

Ídem, pp. 482.

Es decir, en los que puede incurrir una postura católica totalmente acrítica respecto del Magisterio y sus limitaciones.

A. Torres Queiruga, p. 278.

X. Zubiri, "El Cristianismo y la razón moderna", en El problema filosófico de la historia de las religiones, p. 306.

J. R. Geiselmann, "Dogma”, en Conceptos fundamentales de teología I, citado por Tamayo, p. 332.

X. Zubiri, "El Cristianismo y la razón moderna", en El problema filosófico de la historia de las religiones, p. 315-316.

A. Torres Queiruga, pp. 256-257.

X. Zubiri, "El Cristianismo y la razón moderna", en El problema filosófico de la historia de las religiones, p. 308.

A. Torres Queiruga, p. 359.

X. Zubiri, "Historia del dogma", en El problema teologal del hombre: Cristianismo, p. 475.

Es decir, los teólogos neotomistas como Marín-Sola.

X. Zubiri, "El Cristianismo y la razón moderna", en El problema filosófico de la historia de las religiones, p. 311.

A. Torres Queiruga, pp. 409-410. 